\title{
TREATMENT TRIALS OF EPIZOOTIC LYMPHANGITIS WITH LOCAL MEDICINAL PLANTS: A REVIEW
}

\author{
Mersha ASFAW and Tewodros FENTAHUN \\ Unit of Biomedical Sciences, College of Veterinary Medicine and Animal Sciences, University of Gondar, P.O. Box 196, Gondar, Ethiopia. \\ $\triangle$ Email: tedyvet@gmail.com; 00:-00002-2955-5638 \\ Supporting Information
}

\begin{abstract}
The aim of this paper was to review the use of local herbal medicines to treat Epizootic lymphangitis (EZL) and challenges related with safety, efficacy and quality control of herbal medicines. EZL has deleterious effect on both welfare and health of the horses and mules. In addition it has a serious negative impact on mainly the livelihoods of cart-horse owners/drivers. Basically, antifungal drugs for the treatment of EZL are costly and mostly unavailable in such areas especially in developing countries like Ethiopia. Medicinal herbs have a hopeful future since there are about half a million plants around the world, most of them have not yet been studied in medical practice, and current and future studies on medical activities can be effective in treating this disease. Furthermore, there is no gainsaying the fact that the requirements as well as the research protocols, standards and methods needed for the evaluation of the safety and efficacy of herbal medicines are much more complex than those required for conventional pharmaceuticals. These days, there are several trials on local plants like Xanthium strumarium (X. strumarium), Combretum molle (C. molle) seed and Phytolacca dodecandra ( $P$. dodecandra) extracts inhibited the growth of Histoplasma capsulatum var farciminosum $(H$. capsulatum var farciminosum). Among these, the aqueous and $n$-butanol extracts of $P$. dodecandra with minimum inhibitory concentration (MIC) of $(0.078 \%-0.156 \%)$ and $(0.039 \%-0.078 \%)$ respectively have been inhibiting the growth of $H$. capsulatum var. farciminosum. In vivo, over $58.3 \%$ horses with the disease responded to treatment then the other two plant extracts. In conclusion, $P$. dodecandra extracts showed a significant effect to inhibit the growth of $H$. capsulatum var farciminosum in vitro and EZL in vivo.
\end{abstract}

Keywords: Combretum molle, Epizootic lymphangitis, Xanthium stramorium, Phytolacca dodecandra, Medicinal herbs.

\section{INTRODUCTION}

Epizootic lymphangitis (EZL) is a contagious, chronic disease which mainly affects horses, mules, and camels (Biyashev et al., 2019; Adedokun et al., 2020). It is caused by Histoplasma capsulatum var. farciminosum (H. capsulatum var. farciminosum). The disease is characterized clinically by a suppurative, ulcerating, and spreading pyogranulomatous, multifocal dermatitis and lymphangitis. It is seen most commonly in the extremities, chest wall and the neck, but it can also be manifested as an ulcerating conjunctivitis of the palpebral conjunctiva, or rarely as a multifocal pneumonia. The organism may also invade open lesions including ruptured strangles abscesses and castration wounds (OIE, 2009).

The source of the H.capsulatum var. farciminosum can be the skin lesions, nasal and ocular exudates of infected animals or the soil. This organism can also spread on fomites (common utensil) such as grooming or harnessing equipment. Biting flies in the genera Musca and Stomoxys are thought to spread the conjunctival form. The pulmonary form probably develops when the animal inhales the organism (Public Health Agency of Canada, 2001).

Epizootic lymphangitis is more common in tropical and subtropical regions than in temperate zones (Alsaad et al., 2016). H.capsulatum var. farciminosumis endemic in some countries in the Mediterranean region, and in parts of Africa and Asia including India, Pakistan and Japan (OIE, 2009). Many treatment types have been tried, largely without success. Parenteral iodides and amphotericin B have been reported as effective. However, although the disease is highly prevalentand economically important in Ethiopia (Ameni, 2006), the treatment options mentioned have not been employed because of the cost of the drugs and their absence in Ethiopia. This warrants for the need for other approaches including the use of traditional remedies.

Traditional medicine is used throughout the world as it is heavily dependent on locally available plant species and plant-based products and capitalizes on traditional wisdom-repository of knowledge (Awas and Demissew, 2009). The wide spread use of traditional medicine could be attributed to cultural acceptability, economic affordability and efficacy against certain type of diseases as compared to modern medicines. Knowledge of medicinal plants of Ethiopia and of their uses provides vital contribution to human and livestock health care needs throughout the country (Belayneh et al., 
2012). The plant- based human and livestock health care persists and remains as the main alternative treatment for different ailments in Ethiopia, largely due to shortage of pharmaceutical products, prohibitive distance of the health service stations, unaffordable prices by small holder farmers and pastoralists for conventional drugs, emergence and reemergence of certain diseases and appearance of drug resistant microbes and/or helminthes (Bekele et al., 2012).

Whole plant of Xanthium strumanrium (X. strumanrium) as well as all parts separately is used in medicine (Bhogaonkar and Ahmad, 2012; Fan et al., 2019). The genus xanthium also possess antibacterial, antiviral, antimalarial, fungicidal, insecticidal and cytotoxic activities against cancer cell lines (Sravani et al., 2010; Passos et al., 2019). Phytolacca dodecandra ( $P$. dodecandra) is one of the many plants claimed to have antifungal secondary metabolites. The antifungal effect of the crude aqueous extract of $P$. dodecandra was demonstrated in- vitro against different genera of dermatophytes of human pathogen and four clinical isolates of Candida albicans (Woldeamanuel et al., 2005; Tura et al., 2017).

Combretum molle was used as a medicinal plant since ancient times (Grønhaug et al., 2008). The test of $C$. molle seed extract as antifungal property has been demonstrated in various studies (Masoko et al., 2007; Anato and Ketema, 2018). Medicinal herbs have a hopeful future since there are about half a million plants around the world, most of them have not yet been studied in medical practice, and current and future studies on medical activities can be effective in treating diseases (Singh, 2015).

In terms of population exposure alone, it is essential to identify the risks associated with the use of herbal medicines, and in this regard, the safety of these products has become an issue of great public health importance (WHO, 2004; WHO, 2005). There is no gainsaying the fact that the requirements as well as the research protocols, standards and methods needed for the evaluation of the safety and efficacy of herbal medicines are much more complex than those required for conventional or orthodox pharmaceuticals (WHO,2005; Zhou et al., 2013). Thus, the general requirements and methods for quality control of finished herbal products remain far more complex than for other pharmaceuticals (WHO, 2003; WHO, 2004; WHO, 2005). Therefore the main objectives of this paper is to review the commonly used local herbal medicine to treat EZL and challenges related with safety, efficacy and quality control of local herbal medicines.

\section{TREATMENT TRIALS FOR EZL USING HERBAL MEDICINE}

\section{The Xanthium strumarium leaf extract}

The $X$. strumarium, a rough cocklebur is broad leaved, tap rooted herbaceous annual plant. This is in a family of asteraceae, sub family asteroideae, tribe heliantheae, and genus Xanthium and species $X$. strumarium. It grows as weed throughout on waste lands. Cockleburs are short day plants and they can also flower in the tropics where the day length is constant. The herb is reputed as medicine in Europe, China, Indo-china, Malaysia and America also (Bhogaonkar and Ahmad, 2012). Stem is erect, ridged, rough and hairy and frequently branched which results somewhat bushy plants from 30-120 cm tall. It has small greed unisexual flower occurring in separate cluster at the end of the brunches and main stems. The fruit is brown, hard, woody, bur from 0.4-0.8 inch long and coved with stout, hooked bristle. Its seed are produced in hard, spiny, globes or oval double chambered single seeded bur (Agharkar, 1991).

Beside its medicinal values if a small quantity of parts of the mature plants is consumed, the seeds and seedlings will cause intoxication because extremely toxic chemical carboxyatratyloside is contained in them (Madalln and Sing, 2001). Whole plant of $X$. strumanrium as well as all parts separately is used in medicine (Bhogaonkar and Ahmad, 2012). The genus xanthium also possess antibacterial, antiviral, antimalarial, fungicidal, insecticidal and cytotoxic activities against cancer cell lines (Sravani et al., 2010).

Antifungal activity can be determined by the agar diffusion method. Test samples are diluted in Sabouraud dextrose agar followed by solidification in slanting positions. Test fungal cultures are inoculated on the slant and are incubated at $29^{\circ} \mathrm{C}$ for 3-7 days (Paxton, 1991; Nisaret al., 2010). The principal compounds isolated from $X$. strumanriumleaves are found to contain, isoxanthanol, hydroquinone, caffeyolquinic acids, xanthanol, anthraquinone, cardenolide, leucoanthocyanin, simple phenolic striterpenoids and thiazinedione (Bhogaonkar and Ahmad, 2012). X. strumanrium produces secondary metabolites such as alkaloids, tannins, terpenoids, flavonoids, chloroform and n-hexane fractions whose activity has been demonstrated to be antifungal (Gujar and Talwankar, 2012). Antifungal activity of these molecules from $X$. strumarium exhibited $60 \%$ and $50 \%$ inhibition activity against the major dermatophyte fungi, Microsporum canis (Bharathi et al., 2010). 

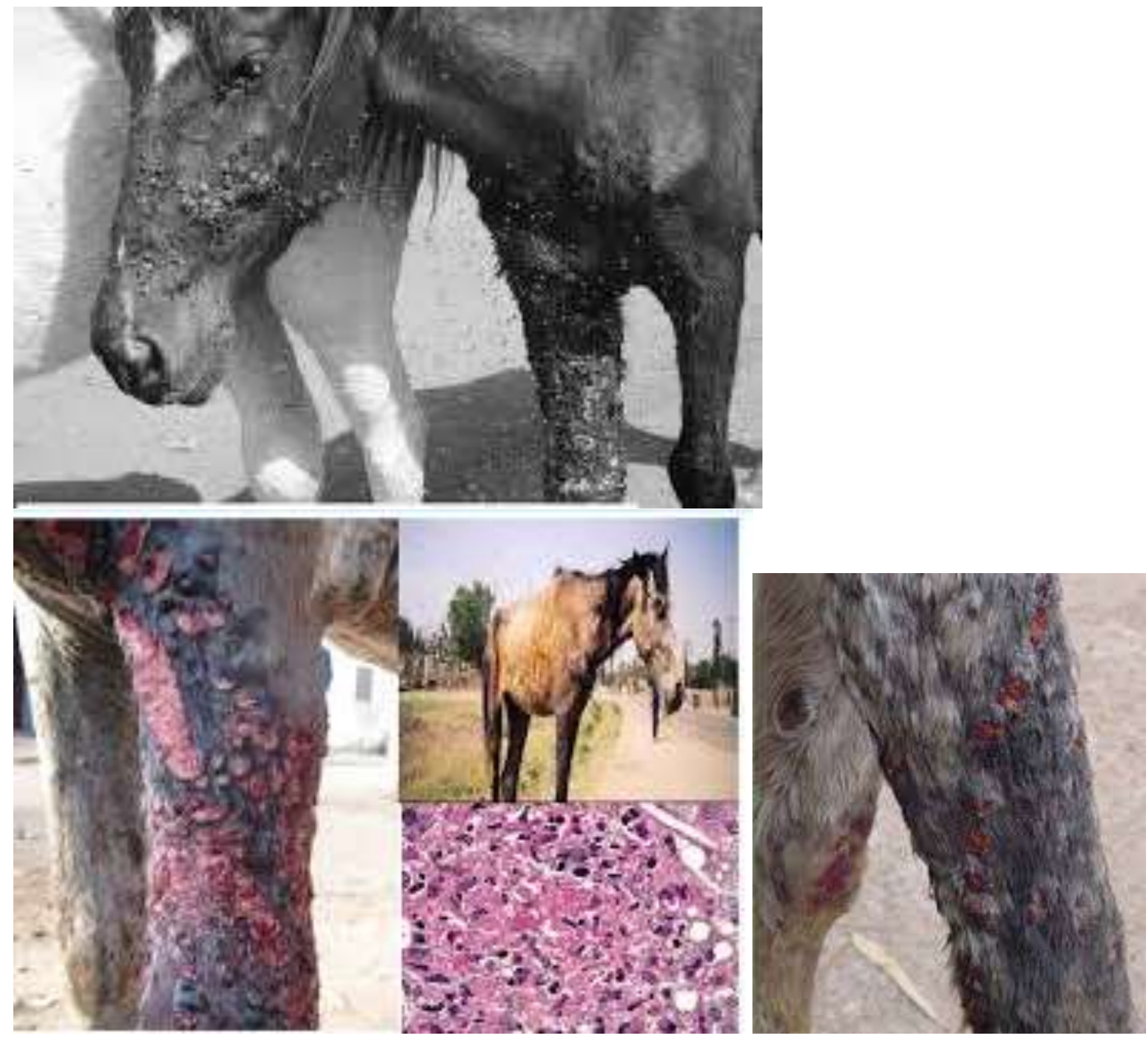

Figure 1 - Lesions of Epizootic lymphangitis (Wondmnew and Teshome, 2016).

\section{The Phytolacca dodecandra extracts}

Antifungal effect is one of the effects of secondary metabolites produced by plants. It is one of the many plants claimed to have antifungal secondary metabolites. Many studies indicated that, saponins are responsible for its antifungal effect. The antifungal effect of the crude aqueous extract of $P$. dodecandrais demonstrated in vitro against different genera of dermatophytes of human pathogen and four clinical isolates of Candida albicans (Woldeamanuel et al., 2005). The crude aqueous extract is also found to have effect against $\boldsymbol{H}$. capsulatum var farciminosum both in- vitro and in- vivo (Ameni and Tilahun, 2003; Hadush et al., 2008). The n-butanol and aqueous extracts of $P$. dodecandra are evaluated for their effects on the isolates of $\boldsymbol{H}$. capsulatum var. farciminosum and for the treatment of cases of epizootic lymphangitis. The phytochemical analysis of $P$. dodecandra shows the presence of saponins, alkaloids, and phenolic compounds in the berries of $P$. dodecandra. Thus, the secondary metabolites identified in the berries are all active antifungal compounds (Arif et al., 2009), which could imply that these secondary metabolites could be responsible for the antifungal activity of the berries observe in the $n$-butanol extract of the berries.

The antifungal effect of $n$-butanol extract is observed to be much greater than that of the aqueous extract. The minimum inhibitory concentration (MIC) of $n$-butanol extracts range from $(0.039 \%-0.078 \%$; whereas that of the aqueous extract is in the range of $(0.625 \%-1.250 \%)$. Similar finding for the aqueous extract is reported in which the MIC of $P$. dodecandra against the yeast forms of different Candida species is higher than $0.5 \%$ (Woldeamanuel et al., 2005). Another study shows that the MIC of the aqueous extract of P.dodecandra is 1\% (Ameni and Tilahun, 2003). The MIC for novel pharmacological compounds should be $<0.1 \%$ (Kuete, 2010).

The minimum fungicidal concentration (MFCs) of aqueous and $n$-butanol extracts of $P$. dodecandra ranges from $(1.250 \%-2.500 \%)$ and $(0.078 \%-0.156 \%)$, respectively. The prepare ointment is topically applied and the result shows that, $58.3 \%$ are completely healed, while $\mathbf{4 1 . 7 \%}$ did not cure. Comparable results are reported with the aqueous extracts (Ameni and Tilahun, 2003; Hadush et al., 2008). The n-butanol extract of $P$. dodecandrais effective against $H$. capsulatum 
var. farciminosum. Previous toxicity studies on $P$. dodecandra indicated that human and guinea pigs can tolerate skin irritation of $P$. dodecandra. Moreover, oral LD50 are found to be 2.6 and $2.2 \mathrm{~g} / \mathrm{kg}$ in mice and rats, respectively (Ameni and Tilahun, 2003; Hadush et al., 2008).

\section{Combretum molle extracts}

Combretum molle (C. molle) is used as a medicinal plant since ancient times (Grønhaug et al., 2008). The test of C.molle seed extract as antifungal property has been demonstrated in various studies (Masoko et al., 2007). Phytochemical studies carried out in the genus Combretum have shown the occurrence of many classes of constituents, including triterpenes, flvonlds, lignans, non-protein amino acid and tannins from different parts of the plant (Pietrovsk et al., 2006). C. molle has been widely used as a medicinal plant to treat various diseases such as parasitic, protozoan, and fungal infectious diseases in East and West Africa (Grønhaug et al., 2008). Antifungal activity is reported in numerous fungal models that used Candida albicans, Candida neoformans, Epidermophyton flccosum, Microsporum gypseum, Trichophyton mentagrophytes, Aspergillus fumigatus, Sporothrix schenckii and Microsporum canis (Masoko et al., 2007).

The minimum inhibitory concentration (MIC) of C.molle seed extracts obtain in the study is $0.0156 \%$. However, the difference between the MIC $(0.0156 \%)$ and the maximum none inhibitory concentration $(0.0078 \%)$ suggests that the MIC could be lower. As Kuete (2010) stated, the MIC for novel pharmacological compounds should be $<0.1 \%$. So, the MIC $(0.0156 \%)$ is below $0.1 \%$ and hence this extract can be considered active. The positive control Ketaconazole is found to be more potent than C.molle seed extracts in inhibiting the growth of the mycelia form of $H$. capsulatum var. farciminosum (Asres et al., 2006). The C.molle seed extracts has inhibitory effect on $H$. capsulatum var. farciminosum. The Minimum inhibitory effect of C.molle seed extracts obtained from the study by Wondmnew and Teshome (2016) is also in harmony with previous studies made on fresh garlic extract $(0.5 \mathrm{mg} / \mathrm{ml}, 0.05 \%)$ by Mesfi (2012), $P$. dodecandra (0.03\%) by Mekonnen et al. (2012). According to a study by Mekonnen et al. (2012), the MICs of $n$-butanol and aqueous extracts of $P$. dodecandra are (0.039\%-0.078\%) and (0.625\%-1.250\%), respectively. The difference in MIC of the two extracts of $P$. dodecandracan be ascribing by the difference in the polarity of the solvent used in the extraction process. This is supported by Masoko et al. (2007); Eloff et al. (2005); and Cowan, (1999), as the polarity of the solvent has great effect on the quantity and types of bio-molecules extract.

The main antifungal molecule in C.molle seed extract is tannin (Mishra et al., 2009). The presence of phenolic hydroxyl groups on the surface of tannin molecules participate strongly in the biological activities of tannins. It combines with protein and other polymers to form stable complexes through nonspecific forces such as hydrogen bonding, hydrophobic effects and covalent binding (Stern et al., 1996). This is done by hydrolysis of ester linkage between gallic acid which eventually affects the biosynthesis of cell wall and cell membrane. Impairment of biosynthesis of cell wall and cell membrane cause to increase the permeability of cell membrane and alterations of cell wall .This leads to decrease cell volume and disjunction of cell membrane from the cell wall (Suraya and Darah, 2002). Moreover, this leads to leakage of internal contents and no more exchange of molecule between cell wall and cell membrane.

As Haslam (1996) tannins have two forms, and these are hydrolysable and condensed tannins which affect fungal growth. In the same study make by Ndip et al. (2007) both hydrolysable and condensed tannins have been found to possess antifungal effect. However, the hydrolysable tannins are found to be more effective against fungi. This is because hydrolysable tannins (gallic acid and ellagic acid) are linked to esters of core molecules which will be hydrolyzed easily while condensed tannins are not susceptible to hydrolysis (Haslam, 1996). In other research done by indicated that the fungicidal effect of the extract is due to the presence of high amount of hydrolysable tannins. In addition to its fungicidal effect, when C.molle seed extract is used topically, it will promote tissue healing, stop bleeding, stop further infection and heal the wound internally. As mentioned by Stephane et al. (2004), the ability of tannins to form a protective layer over the exposed tissue keeps the wound from being infected even more.

\section{Challenges associated with monitoring safety of local Herbal Medicine for EZL}

In terms of equine exposure alone, it is essential to identify the risks associated with the use of local herbal medicines, and in this regard, the safety of these products has become an issue of great animal health importance (WHO, 2004; WHO, 2005). There is no doubt that the increasing cases of poisoning associated with the use of local herbal medicines in many parts of the world in recent times, is necessitating the need to ensure thorough toxicity assessment alongside active pharmacovigilance on these products in order to promote their safe use and protect animal health (Zhou et al., 2013).

\section{Challenges related to the assessment of safety and efficacy of local Herbal Medicine}

There is no gainsaying the fact that the requirements as well as the research protocols, standards and methods needed for the evaluation of the safety and efficacy of local herbal medicines are much more complex than those required for conventional or orthodox pharmaceuticals (WHO, 2005; Zhou et al., 2013). A single local herbal medicine or medicinal plant may contain hundreds of natural constituents, and a mixed local herbal medicinal product may contain several times that number. Suppose every active ingredient is to be isolated from individual herb from which the local herbal medicine is formulated or produced, the time and resources required would be tremendous. Such an analysis may practically be impossible especially where local herbal product is a mixture of two or more herbs (WHO, 2005). 


\section{Medicinal herbs in the future perspectives}

Medicinal herbs have a hopeful future since there are about half a million plants around the world, most of them have not yet been studied in medical practice, and current and future studies on medical activities can be effective in treating such diseases (Singh, 2015). The use of medicinal plants has a long history; however, the use of the whole plant or raw materials for treatment or experimentation has many drawbacks, including changes in the plant's compounds in different climates, simultaneous development of synergistic compounds that lead to adverse effects of antagonists, or other unexpected changes in bioactivity, and changes or loss of bioactivity due to the variability and accumulation, storage and preparation of raw materials; therefore, advancing towards the isolation of compounds and the use of pure substances with bioactivity, instead of the plant benefits, has certain benefits including convenient examination of therapeutic effects and determination of toxic doses to control the quality of the therapeutic formulation (Zhang, 2011). The beginning of the development of herbal medicines is concurrent with the development of chemistry and isolation, purification, and determination of plant compounds (Shakya et al., 2012).

In the past, the drug discovery of the biological compounds from plant materials and the process of identifying the structures of active compounds from the extracts are problematic depending on the complexity of the compounds and might take weeks, months or even years. Nowadays, the rate of bioassay-guided fractionation has been significantly enhanced by the development of precision instruments such as high-performance liquid chromatography (HPLC), liquid chromatography mass spectrometry (LCMS), magnetic field and nuclear magnetic resonance (NMR) is a recent major breakthrough for the categorization (NMR) is a recent major breakthrough for the categorization of compounds that are extremely limited in quantity in their organisms of origin (Schroeder and Gronquist, 2006). Despite the success of research to produce medicinal plants over the past few decades, future efforts face many challenges. The quality of the herbal product has been studied. Standardization of raw materials is an important issue for the plant industry (Yadav et al., 2014).

Herbaceous plants can be easily infected during growth, processing and collection. Contamination and pollution with heavy metals are two main problems with herbal drugs. It is therefore necessary to improve the quality and quantity of bioactive compounds for the production of herbal drugs while making effort to discover more new herbal drugs (Clark, 1996). Due to expanding the use of natural substances around the world, the quality and safety ofplant-derived medicines should be comprehensively and accurately studied issues and the traditional and the millennial beliefs about these issues cannot be surely trusted; therefore, scientific and enlightening studies are essential to obtain reliable information for the use of medicinal plants in health care (Firenzuoli and Gori, 2007).

Table 1 - Results of the in vitro evaluation of methanol extracts of $P$. Dodecandra, C. longa, and $D$. stramonium on $H$. capsulatum var. farciminosum

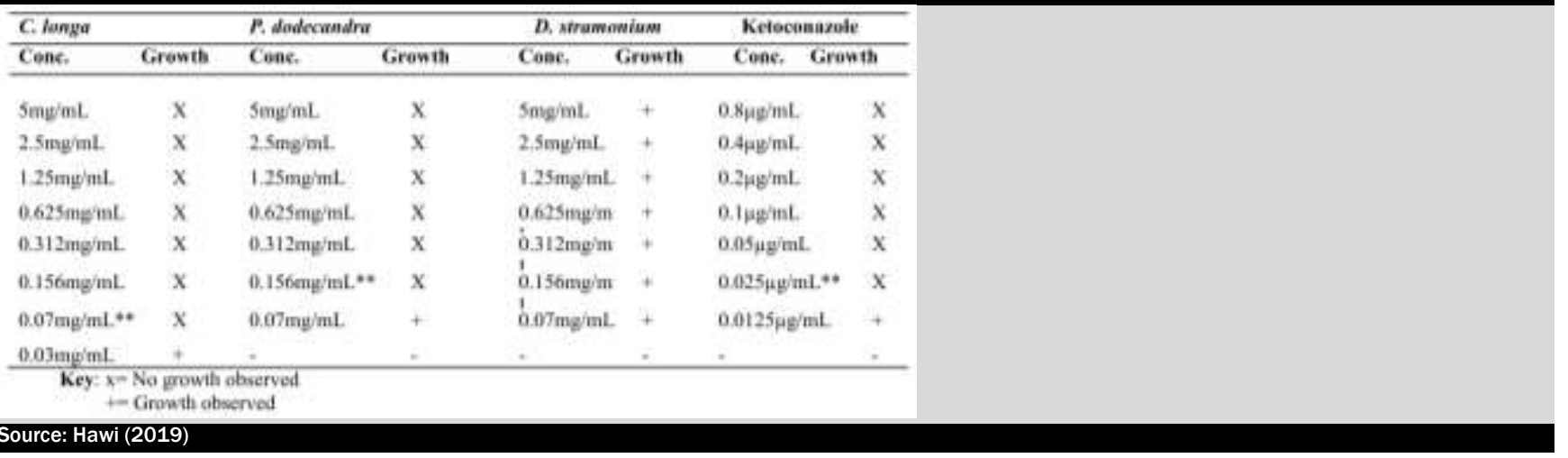

\section{Table 2 - Growth of HCF in different concentrations of C.molle seed extract and ketoconazole}

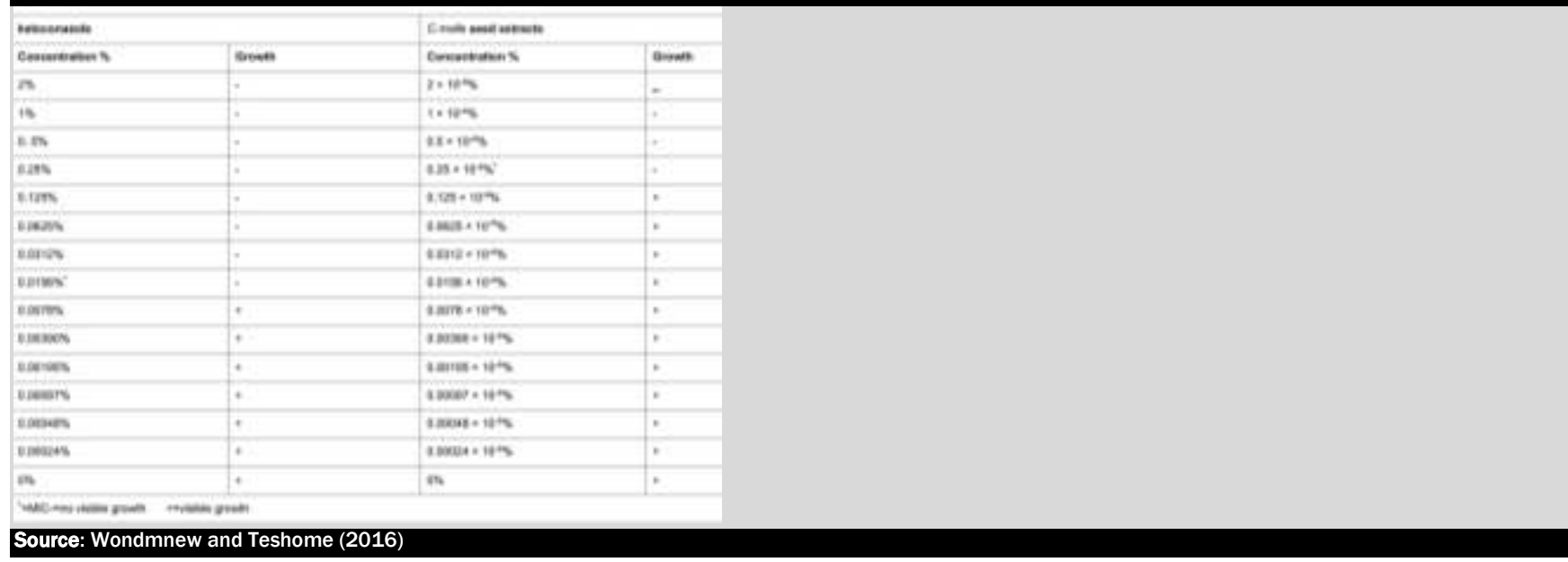



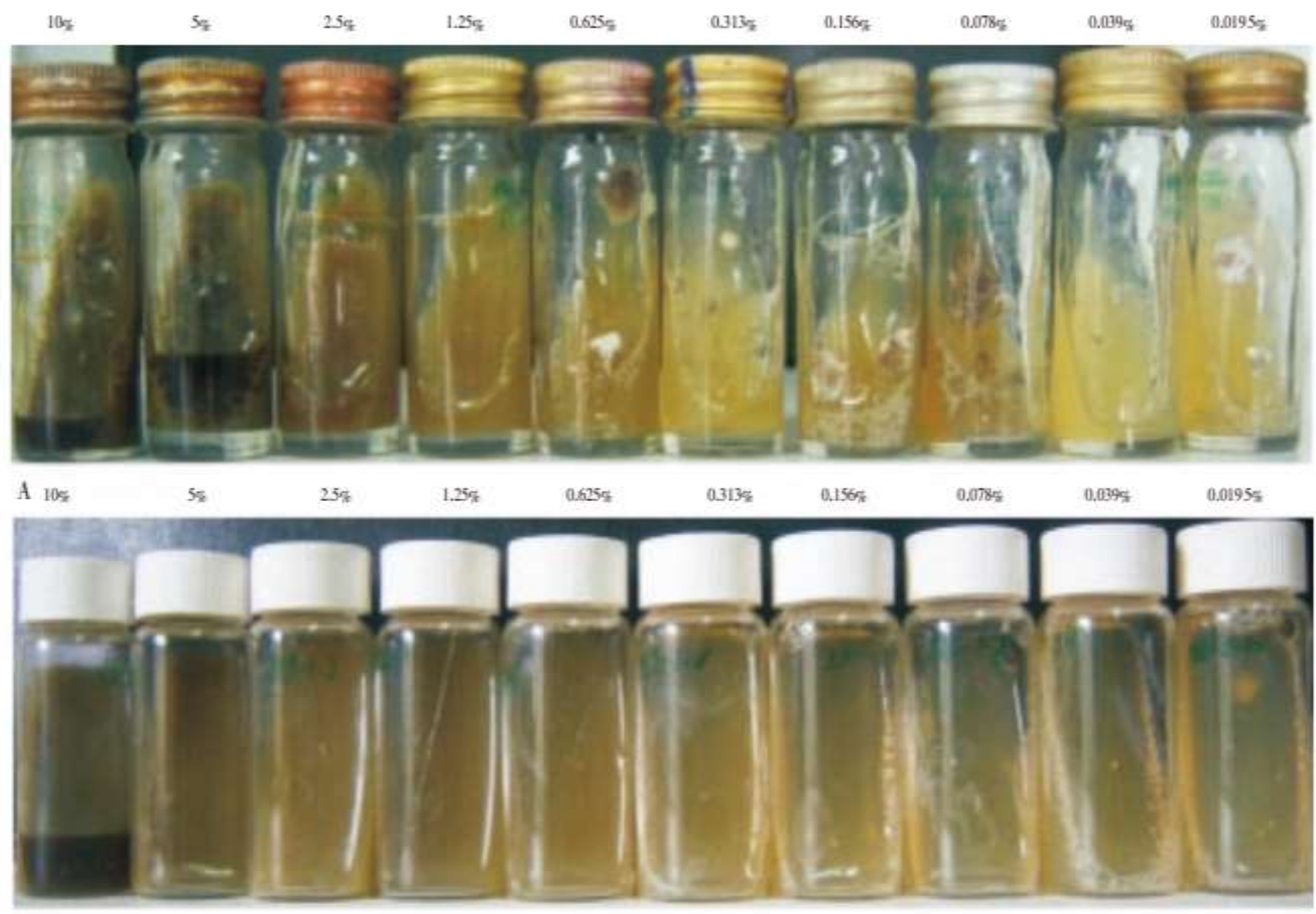

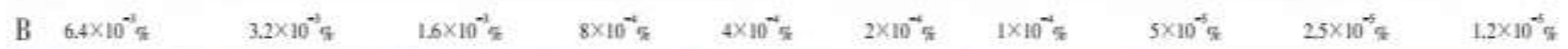

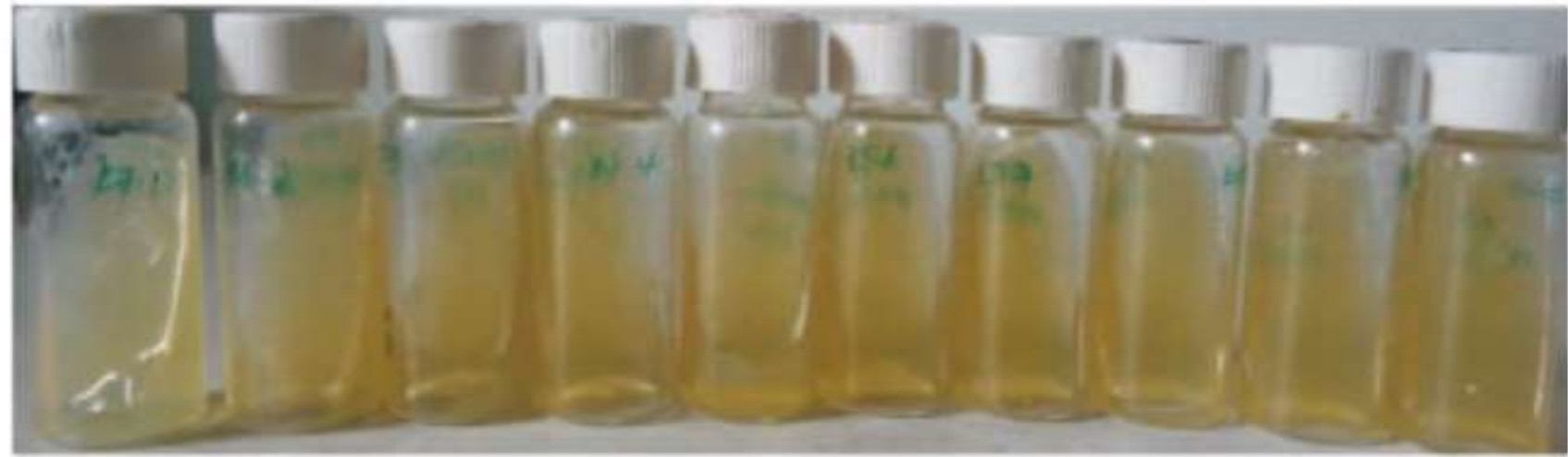

C

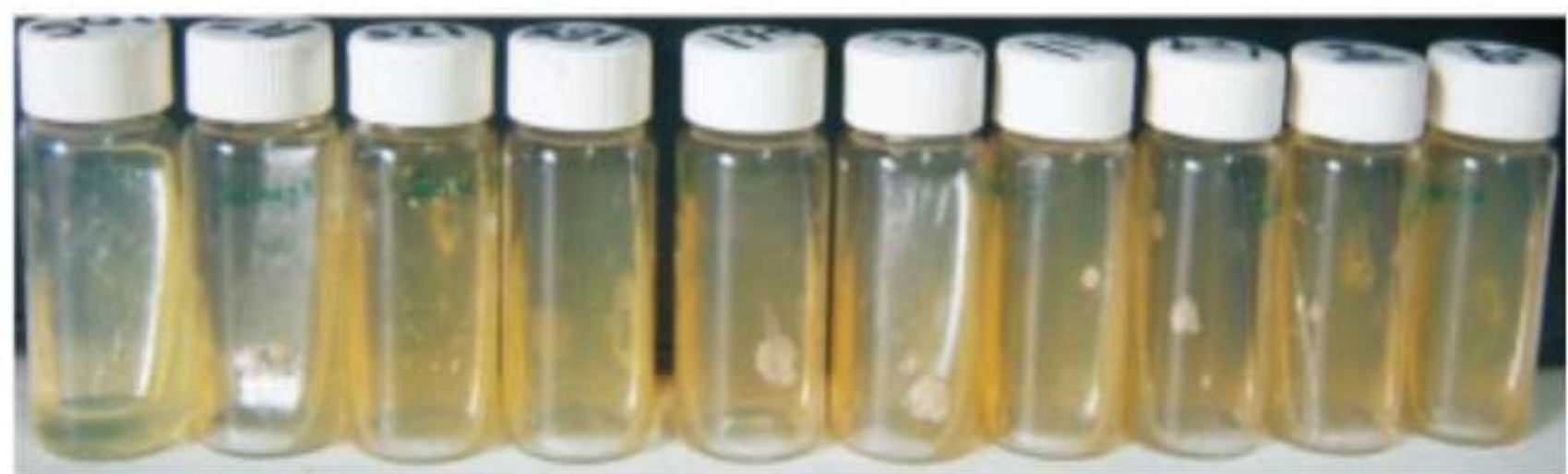

D

Figure 2 - The MICs of aqueous and n-butanol extracts of $P$. dodecandra against $H$. capsulatum var. farciminosum. A: MIC of aqueous extract: growth was observed starting at $0.625 \%$; B: MIC of $n$-butanol extract: growth was observed starting from $0.039 \%$; C: MIC of ketoconazole (standard): growth was observed at a concentration of 1.2×10-5\%; D: Saline diluted Sabourauds dextrose agar (negative control): growth was observed in all agar plates (Mekonen et al., 2012). 
The $X$. strumarium leaf extract has strong inhibitory effect on the growth of the mycelial form of $H$. capsulatum var. farciminosum. The $X$. strumarium leaf extract can be included in the treatment of epizootic lymphangitis provided that convenient methods of preparation, dose and route of administration should be established through rigorous in -vitro and in -vivo trials. The n-butanol extract of $P$. dodecandra demonstrated minimum inhibitory concentration (MIC) and minimum fungicidal concentration (MFC) values that are considered to have antifungal properties. Therefore, since antifungals are not available for veterinary use in Ethiopia and also as they are expensive; searching for available and affordable antifungals such as n-butanol extract of $P$. dodecandra is recommended for the treatment of epizootic lymphangitis. The investigation of chemical compounds from natural products is fundamentally important for the development of new drugs. Ethanol macerated $C$. molle seed extract have a promising anti-fungal effect on mycelial form of $H$. capsulatum var. farciminosum. The main anti-fungal molecule in $C$. molle seed extract is hydrolysable tannins. The main action of tannin on $\mathrm{H}$. capsulatum var. farciminosum is inhibition of cell wall and cell membrane biosynthesis. In topical application tannin has haemostatic and wound closure effect. The $C$. molle seed can be used for the treatment of epizootic lymphangitis if convenient methods of preparation, dose, and route of administration are established through meticulous in vitro and in-vivo trials. Medicinal herbs have a hopeful future since there are about half a million plants around the world, most of them have not yet been studied in medical practice, and current and future studies on medical activities can be effective in treating diseases. Those all parts of the plant have the chemicals upon extraction, the seed of the plants primarily and leaves secondly are preferable than the other parts of the particular plant because the seeds have higher concentration of the ingredients or chemicals required to use. The combination of the results got from both in vivo and in vitro trials are mandatory to witness the effectiveness of the particular plant's medicinal value.

Based on the above conclusions the following recommendations are forwarded: The appropriate treatment decision should be achieved to avoid suffering of equine from EZL. Challenges related with safety, efficacy and quality control of local herbal medicines for EL should be avoided. Any other local herbal medicines should be tried on EZL like "embuay and ambacho". In-vivo studies must be conducted so that the safety margin, toxicity and cure rates will be known in order to use them commercially. Study on the mechanism action of the local herbal medicine extracts and their toxic effect on lab animals should be reported .Antifungal drug should be produced by using herbal medicines that serve to cure the disease and shall be scale up later at industry level.

\section{DECLARATIONS}

Corresponding author

Email: tedyvet@gmail.com; 0 0000-0002-2955-5638

\section{Authors' contribution}

All the three authors reviewed the paper and contributed in developing the content.

\section{Conflict of interest}

The authors declare they have no competing of interests.

\section{REFERENCES}

Adedokun RAM, Fagbohun OA, Akinlabi EY (2020). Clinicopathological features, molecular diagnosis and treatment of epizootic lymphangitis in a donkey at a university zoological garden: a case report. Comparative Clinical Pathology, 2020: In Press. DOI: https://doi.org/10.1007/s00580-020-03112-0.

Agharkar SP (1991). Medicinal plant of Bombyprecidency. Scientific publishers, Jodhpur (India), pp. $852-857$.

Alsaad, KM, AL-Amery MAY, Muhsen RK (2016).Epizooticlymphangitis in drought horse of basrah province, (a case report). Basrah Journal of Veterinary Research, 15: 228-232. Link: https://www.iasj.net/iasj?func=fulltext\&ald=124266.

Ameni G and Tilahun G. (2003). Preliminary laboratory and field evaluation of Endod for treatment of epizootic lymphangitis. Bulletin of Animal Health and Production Africa, 51:153-160.

Ameni G (2006). Epidemiology of equine histoplasmosis (epizootic lymphangitis) in carthorses in Ethiopia. Veterinary Journal, 172:160165. Link: https://doi.org/10.1016/j.tvjl.2005.02.025.

Anato, M and Ketema, T (2018). Anti-plasmodial activities of Combretummolle (Combretaceae) [Zwoo] seed extract in Swiss albino mice. BMC Research Notes, 11(1): 312. https://doi.org/10.1186/s13104-018-3424-4.

Ansari JA and Inamdar NN (2010). The promise of traditional medicines.International Journal of Pharmacology; 6(6):808-812. Dol: https://doi.org/10.3923/ijp.2010.808.812.

Arif T, Bhosale JD, Kumar N, Mandal JK, Bendre RS, Lavekar GS(2009).Natural products-antifungal agents derived from plants. Journal of Asian Natural Production Research, 11(7): 621-638. DOI: https://doi.org/10.1080/10286020902942350.

Asres K, Mazumder A, Bucar F (2006).Antibacterial and antifungal activities of extracts of combretummolle. Ethiopian Medical Journal, 44: 269-277. Link: https://pubmed.ncbi.nlm.nih.gov/17447394/

Awas T and Demissew S (2009). Ethnobotanical study of medicinal plants in Kafficho people, southwestern Ethiopia. In Proceedings of the $1^{\text {th }}$ International Conference of Ethiopian Studies. Edited by Svein E, Harald A, Birhanu T, Shiferaw B. Trondheim, Norway; NTNU-Trykk Press 2009, 3:711 -726. Link: https://www.harrassowitz-verlag.de/dzo/artikel/201/003/3989_201.pdf?t=1309428997 
Bekele D, Asfaw Z, Petros B, Tekie H (2012). Ethno-botanical study of plants used for protection against insect bite and for the treatment of livestock health problems in rural areas of Akaki District, Eastern Shewa, Ethiopia. Topclass Journal of Herbal Medicine, 1:40-52. Available online at http://www.topclassglobaljournals.org.

Belayneh A, Asfaw Z, Demissew S, Bussa F. (2012). Medicinal plants potential and use by pastoral and agro-pastoral communities in Erer Valley of Babile Woreda, Eastern Ethiopia. Journal of Ethnobiology and Ethnomedicine, 8: 12. DOI: https://doi.org/10.1186/17464269-8-42.

Bharathi BR, Padmini D, Swamidoss and Gorge, T (2010).Phytochemichal analysis and antibacterial activity of Solanum trilobatum against HIV associated bacterial pathogens. International Journal of Pharmaceutical Sciences and Research, 2(2): $598-605$.

Bhogaonkar, PY and Ahmad SA (2012).Pharmacognostic studies on Xanthium strumarium. A Folk Unani Medicinal Herb, Bioscience Discovery, 3(1): 101-106.

Biyashev KB, Zhylkaidar AZ, Zhanabai SD, Altenov AE, Shayakhmet EB (2019). Lymphangitis in camels. Advances in Animal and Veterinary Sciences 7(s1): 6-8.Doi: http://dx.doi. org/10.17582/ journal.aavs/2019/7.s1.6.8

Clark AM (1996). Natural Products as a Resource for New Drugs. Pharmaceutical Research, 13(8): 1133-41. doi: https://doi.org/10.1023/a:1016091631721.

Cowan MM (1999). Plant products as antimicrobial agents. Clinical Microbiology Review, 12: 564-582. DOI: https://doi.org/10.1128/CMR.12.4.564.

Eloff J, Famakin J, Katerere D (2005). Isolation of antibacterial stilbene from Combretumwoodii (Combretaceae) leaves. African Journal of Biotechnology, 4:1167-1171. Available online at http://www.academicjournals.org/AJB.

Fan Fan W, Fan L, Peng C, Zhang Q, Wang L, Li L, Wang J, Zhang D, Peng W, Wu C (2019). Traditional Uses, Botany, Phytochemistry, Pharmacology, Pharmacokinetics and Toxicology of Xanthium strumarium L.: A Review. Molecules, 24(2): 359. https://doi.org/10.3390/molecules24020359.

Fazli K, Zafar I, Ayub K, Zakiullah F and Muhammad SK (2012). Validation of some of the ethnopharmacological uses of Xanthium strumarium and Duchesneaindica, Pak. Journal of Botany, 44(4): 1199-1201. Available at: https://www.researchgate.net/publication/236329105 Validation of some of the ethnopharmacological uses of Xanthium stru marium_and_Duchesnea_Indica.

Firenzuoli F and Gori L (2007). Herbal medicine today: clinical and research issues. Evid Based Complement Alternat Medicine; 4(Suppl 1):37-40. doi: https://doi.org/10.1093/ecam/nem096.

Grønhaug TE, Glaeserud S, Skogsrud M, Ballo N, Bah S (2008). Ethno-pharmacological survey of six medicinal plants from Mali, WestAfrica. Journal of Ethnobiol Ethnomedicine, 4: 26. DOI: https://doi.org/10.1186/1746-4269-4-26.

Gujar J and D Talwankar (2012). Antifungal potential of crude plant extract on some pathogenic fungi, World Journal of Science and Technology, 2(6): 58-62.

Hadush B, Ameni G, Medhin G (2008). Equine histoplasmosis: treatment trial in cart horses in Central Ethiopia. Tropical Animal Health Production; 40:407-411. DOI: https://doi.org/10.1007/s11250-007-9099-9.

Haslam E (1996). Natural polyphenols (vegetable tannins) as drugs: possible modes of action. Journal of Natural Production, 59: 205-215. Available at https://pubs.acs.org/doi/10.1021/np960040+.

Hawi J (2019). Assessment of Histofarcin Skin test and In vitro Evaluation of Effects of SelectedMedicinal Plants on the Growth Inhibition of Mycelial form of Histoplasma capsulatumvar. farciminosum. DVM thesis, College of Veterinary Medicine and Agriculture, Addis Ababa University, Debre Zeit, Ethiopia.

Kuete V( 2010). Potential of Cameroonian plants and derived products against microbial infections: a review. Planta Medicine; 76:14791491. DOI:10.1055/s-0030-1250027.

Madalln, RL and JP Sing (2001). Diseases, Competitors' moulds and physiological disorders of button mushroom and their management, Journal of Chafan Singh Haryana, 30(1): 193-194.

Masoko P, Picard J, Eloff, JN (2007).The antifungal activity of twenty four Southern African Combretum species. South African Journal of Botany, 73: 173-183. DOI: https://doi.org/10.1016/j.sajb.2006.09.010.

Mekonnen N, Eyasu M, Nigatu ,A and Gobena A (2012). Evaluation of berries of Phytolacca dodecandra for growth inhibition of Histoplasma capsulatum var. farciminosum and treatment of cases of epizootic lymphangitis in Ethiopia. Asian Pacific Journal of Tropical Biomedicine, 2(7): 505-510. 2(7): 505-510. DOI: 10.1016/S2221-1691(12)60086-0.

Mesfi M (2012). Inhibitory effect of Fresh Garlic Extract on the Growth of the mycelial form of Hcf - an in vitro trial, DVM thesis, College of Veterinary Medicine and Agriculture, Addis Ababa University, Addis Ababa, Ethiopia.

Mishra AK, Mishra A, Kehri H, Sharma B, Pandey A (2009). Inhibitory activity of Indian spice plant, Cinnamomumzeylanicum, extracts against the pathogenic Dematiaceous moulds. Ann Clinical Microbiology and Antimicrobial, 8: 9-15. D0I: 10.1186/1476-0711-8-9.

Nasrin F(2014). Antimicrobial and cytotoxic activity of ethyl acetate, chloroform and n-hexane extracts of cucumissativus leaves, International Journal of Science and Technology, 21(3): 1480-1486. Corpus ID: 38124088. Google Scholar I Link

National Institute of Health (NIH) Office of Dietary Supplements, (2011). Kava. Available at: http://ods.od.nih.gov/Health Information/kava.aspx.

Ndip RN, MalangeTarkang AE, Mbullah SM, Luma HN, Malongue A (2007).In vitro anti-Helicobacter pylori activity of extracts of selected medicinal plants from North West Cameroon. Journal of Ethnopharmacology, 114: 452-457. Available at https://agris.fao.org/agrissearch/search.do?recordID=US201300837480.

Nisar M, Kaleem WA, Qayum M, Abrar H, Zia-ul-haq M, Ali I and Choudhary MI (2011). Biological screening of zizyphus oxyphylla Edgew leaves. Pakistan. Journal of Botany, 43(1): 311-7. Google Scholar

OIE (2009). Update for epizootic Iymphangitis. USA: Center for Food Security and Public Health (CFSPH), and Institute for International Cooperation in Animal Biologics, an OIE Collaborating Centre; 2009, p. 1-4.

Passos MS., Carvalho J, Almir R , Boeno, SI, VLorena de LGlória,Sanderson Dias, Ventura, Thatiana Lopes Biá, Lassounskaia, Elena, BrazFilho, Raimundo, \& Vieira, Ivo J Curcino (2019). Terpenoids isolated from Azadirachtaindica roots and biological activities. Revista Brasileira de Farmacognosia, 29(1): 40-45. https://doi.org/10. 1016/j.bjp.2018. 12.003

Paxton JD (1991). Assay for antifungal activity. Academic Press, London. Wolfe Medical Publications Ltd. London, England. New combination for Histoplasma farciminosum. Mycologia, 77: 964-970.

Pietrovski EF, Rosa KA, Facundo VA, Rios K, Marques MC (2006). Antinociceptive properties of the ethanolic extract and of the triterpene3beta, 6beta, 16beta-trihidroxilup-20(29)-ene obtained from the flowers of Combretuml eprosum in mice. Pharmacology Biochemistry and Behavior, 83: 90-99. Google Scholar I https://doi.org/10.1016/j.pbb.2005.12.010 
Public Health Agency of Canada (2001).Material Safety Data Sheet-Histoplasmacapsulatum. Office of Laboratory Security, p: 1-4. Available at https://www.ndsu.edu/file admin/policesafety/docs/bio_CanadianBiosafety Standardsand Guidelines.pdf.

Schroeder FC, Gronquist M (2006). Extending the scope of NMR spectroscopy with microcoilprobes. Angew Chemistry International England, 45(43):7122-31. doi: 10.1002/anie.200601789.

Shakya AK, Sharma N, Saxena M, Shrivastava S, Shukla S (2012). Evaluation of the antioxidant and hepatoprotective effect of Majoon-eDabeed-ul-ward against carbon tetrachloride induced liver injury. Experimental Toxicology and Pathology, 64(7-8):767- 73. doi: 10.1016/j.etp.2011.01.014.

Singh R (2015). Medicinal plants: A review. Journal of Plant Science; 3(1-1):50-5. doi: 10.11648/j.jps.s.2015030101.18.

Sravani P, Mohana Lakshmi S, Kumar S (2010). Evaluation of Diuretic Activity of Xanthium strumarium, International Journal of Preclinical and Pharmaceutical Research, 1(1): 31-34. Google Scholar I Available at Link

Stephane Q, Tatiana V, Diana K, Michael J, Patrick P (2004). Main structural and stereochemical aspects of the antiherpetic activity of nonahydroxyterphenoyl-containing C-glycosidic ellagitannins. Chemistry and biodiversity, 1(2): 247-58.

SternJL, Hagerman AE, Steinberg PD, Mason PK. (1996). Phlorotannin protein interactions. Journal of Chemistry and Ecology, 22: 18771899. doi: 10.1007/BF02028510.

Suraya S and Darah I (2002). Scanning Electron Microscope studies of the structural modification of Candida albicans cells aier treatment with extract from Cuculigolatifolia, 15-17.

Tura GT, Eshete WB and Tucho GT (2017). Antibacterial efficacy of local plants and their contribution to public health in rural Ethiopia. Antimicrobial Resistance and Infection Control, 6(1):1-7 https://doi.org/10.1186/s13756-017-0236-6.

U.S. Food and Drug Administration (2011). Regulatory Framework of DSHEA of1994. Available at: http://www.fda.gov/NewsEvents/Testimony/ucm115163.htm.

U.S. Food and Drug Administration (2012). Dietary Supplement Healthand Education Act of 1994 . Available at: http://www.fda.gov/RegulatoryInformation/Legislation/FederalFoodDrugandCosmeticActFDCAct/SignificantAmendmentstotheFDCAc t/ucm148003.htm

WHO (2003). WHO Guidelines on Good Agricultural and Collection Practices (GACP) for Medicinal Plants. Geneva, Switzerland: World Health Organization. Available at: $\underline{\text { http://www.who.int/medicines/library/trm/medicinalplants/agricultural.pdf. }}$

World Health Organization. (2004). WHO guidelines on safety monitoring of herbal medicines in pharmacovigilance systems. World Health Organization. Available at: https://apps.who.int/iris/handle/10665/43034.

World Health Organization. Programme on Traditional Medicine (2005). National policy on traditional medicine and regulation of herbal medicines : report of a WHO global survey. World Health Organization. https://apps.who.int/iris/handle/10665/43229

Woldeamanuel Y, Abate G, Chryssanthou E (2005). In- vitro activity of Phytolaccadodecandra (Endod) against dermatophytes. Ethiopian Medical Journal 43(1): 31-34. PMID: 16370528.

WondmnewK and Teshome D (2016). The effect of Combertum molle seed extracts on the Growth of the Mycelial Form of Histoplasma capsulatum var farciminosum and In Vitro Trial. Virology and Mycology, 5:154. doi: https://doi.org/10.4172/2161-0517.1000154.

Yadav M, Chatterji, S, Gupta, SK, Watal, G (2014). Preliminary phytochemical screening of six medicinal plants used in traditional medicine. International Journal Pharm Science, 6(5): 539- 42. Available at https://innovareacademics.in/journal/ijpps/Vol6lssue5/9439.pdf.

Yirga G (2010). Ethnobotanical study of medicinal plants in and around Alamata, Southern Tigray, Northern Ethiopia. Current Research Journal Biological Science, 2(5): 338-344. Google Scholar I Link

Zhang H (2011). Bioactive Natural Products: Detection, Isolation, and Structural Determination. Phytomedicine; 18(10): 902-3. ISBN 9780849372582. Google Scholar I Available on Taylor \& Francis eBooks

Zhou J, Ouedraogo, M, Qu, F, and Duez, P (2013). Potential genotoxicity of traditional Chinese medicinal plants and phytochemicals: an over view. Phytotherm Research. DOI: https://doi.org/10.1002/ptr.4942 